\title{
Optimal placement of water-level sensors to facilitate data- driven management of hydrological infrastructure assets in coastal mega-cities of developing nations
}

\author{
R.I. Ogie ${ }^{* 1}$, N. Shukla ${ }^{1}$, F. Sedlar ${ }^{2}$, and T. Holderness ${ }^{3}$ \\ ${ }^{1}$ Smart Infrastructure Facility, University of Wollongong, Northfields Ave, Wollongong NSW 2522, Australia \\ ${ }^{2}$ Department of Civil and Environmental Engineering, University of Michigan, Ann Arbor, MI 48109 USA \\ ${ }^{3}$ The Urban Risk Lab, Massachusetts Institute of Technology, Cambridge MA 02139 USA \\ * Corresponding Author
}

Email: rogie@uow.edu.au

Phone: +61 (0) 242392535 


\section{Abstract}

Management decisions, including real-time control of hydrological infrastructure assets such as drainage channels or waterways, floodgates, pumping stations, etc. are crucial for the sustainability of flood-prone coastal mega-cities. The veracity of such crucial flood control decisions depends heavily on the availability of city-wide, real-time water-level data which is often lacking in developing countries. Smart sensors can reliably provide the required data, but installing one of these devices in every single point in the hydrological network is not economically feasible. This study proposes a methodology for finding optimal locations for the placement of a limited number of water-level sensors, such that the acquired data are most relevant for facilitating informed decisions about management of the flood control infrastructure in different parts of a coastal city. The proposed methodology entails defining a set of optimisation objectives and constraint, which are then assessed computationally at each potential sensor location through the topological/connectivity analysis of a city-wide, graph-based hydrological infrastructure network. The computed values are then utilised in an optimisation algorithm (NSGA-II) to determine the optimal locations for the placement of a limited number of sensors. The usefulness of the proposed methodology is demonstrated in deploying water-level sensors in the city of Jakarta.

Keywords: sensor placement; coastal cities; flooding; graph theory; flood control; drainage network; Jakarta, optimisation; developing countries; mega-cities

\subsection{Introduction}

Flooding in coastal urban areas is a growing problem that requires proper management and control (Yamashita et al., 2016). With global climate change, extreme weather events such as sea-level rise and floods are expected to occur more frequently and in greater intensity (Lau et al., 2010). Previous occurrences of flooding events have shown that the damage caused by floods can be quite significant and coastal mega-cities situated in developing nations suffer the most losses for obvious reasons- the geography of these cities combined with rapid urbanisation, population explosion, and inadequate flood monitoring and control infrastructure make them highly exposed to flood hazards (Few, 2003; Hallegatte et al., 2013; Li, 2003). For example, the economic losses arising from natural hazards, including floods, are approximately 20 times higher in developing countries and the average number of victims is 150 times greater than those in developed nations (Wenzel et al., 2007).

In response to the problem of flooding, coastal cities often rely on engineering interventions that work based on an efficient management of the hydrological infrastructure assets (Caljouw et al., 2005). These hydrological infrastructure assets include waterways or drainage channels, pumping stations, floodgates, etc. (Ogie et al., 2016). The pumping stations are used to remove accumulating floodwater from low-lying areas, where gravity-fed drainage is naturally poor 
(Tingsanchali, 2012) while the floodgates help to control the flow of water by either keeping the gates closed or opened, depending on potential flood threats to dry lands and populated areas located downstream (Sims 2013). The hydraulic components, i.e. pumping stations and floodgates, are often widely distributed within coastal cities and connected spatially through waterways, creating a complex topology of large-scale, geographically extensive networks (Barrat et al., 2004; Hung et al., 2009; Ogie et al., 2016).

In a complex city-scale hydrological infrastructure network, it is difficult to attain optimal outcomes in real-time monitoring and control of floods, especially when the hydraulic infrastructure can only be operated or controlled manually (Malano et al., 1999). This issue is well managed in developed countries, where flood control assets are often fitted with sensors, actuators and embedded controllers to create a smart/intelligent cyber-physical network of infrastructure that are able to automatically detect changes in their environment and self-regulate their operations accordingly (Cembrano et al., 2004). However, in the developing nations where government funding is limited and the uptake of new technology is slow, the situation is different (Adenle et al., 2015). The hydrological infrastructure assets in many of the coastal cities situated in developing nations are still being managed by manual or primitive methods, without adequate situational information about unfolding flood conditions in different parts of these cities (Nasir and Muhammad, 2011). For example, the coastal mega-city of Jakarta relies on just 11 known functional water-level gauges to monitor a complex network of approximately $1092 \mathrm{~km}$ length of waterways, in order to manage flood conditions using 71 pumping stations and 30 floodgates that are mostly operated manually (Ogie et al., 2016). This data-starved approach to flood monitoring and control results in imprecise operational decisions and suboptimal outcomes (Nasir and Muhammad, 2011). Coastal mega-cities in developing nations are therefore faced with a significant problem in which ill-informed operations of the ageing and fragile hydrological infrastructure system exacerbates the flood hazards, causing significant loss of life and damage to property worth billions of dollars (Brinkman and Hartman, 2008; Costa et al., 2016; Few, 2003).

To improve the outcome of structural measures to flood control in developing nations, an economically viable solution is required, which provides infrastructure operators with real-time data about water heights in different parts of the city (Alexander, 1991; Sedlar, 2016; Valdes and Marco, 1995). With the rapid growth in urban applications of low-cost, high-performance sensor technology, no doubt real-time data from a sensor network would facilitate data-driven management of the hydrological infrastructure assets, potentially resulting in improved flood control decisions in coastal mega-cities of developing nations (Akyildiz et al., 2002). A viable solution would therefore require additional water-level sensors or gauges to be placed in strategic locations within the hydrological infrastructure network. Clearly, if every single point in the hydrological network could be monitored, then maximum information about flood conditions in different parts of the city could be attained (Kessler et al., 1998; Preis et al., 2011). Given that this ideal situation is 
not economically feasible, particularly in developing countries where funding is limited, the key question is how does one determine the optimal locations for the placement of a limited number of water-level sensors in order to collect water height information that are most relevant for efficiently operating the existing hydrological infrastructure assets situated in different parts of the city?

The above problem requires a sensor placement strategy, which may be based on expert opinion and/or an optimisation method (Hart and Murray, 2010). The accumulated knowledge and experience of domain experts can be used solely to rank and select potential sensor locations, but this approach overlooks more advantageous designs that can only be derived numerically by an optimisation method (Berry et al., 2005; De Stefano et al., 2015; Hart and Murray, 2010). Several optimisation methods, including genetic algorithm \& evolutionary programming (e.g., Guan et al., 2006; Preis and Ostfeld, 2006; 2008; Shukla et al., 2015), fuzzy systems (e.g., Islam et al., 2011; Vamvakeridou-Lyroudia et al., 2005), simulated annealing (e.g., Chiu and Lin, 2004; Krause et al., 2008a; Shukla et al., 2009) and tabu search (e.g., Aitsaadi et al., 2009; Güney et al., 2012) already exist for determining optimal locations for sensor placement. However, the key challenge in applying any optimisation method lies in the formulation of the problem and the selection of optimisation objectives, constraints, and modeling assumptions - factors that often vary with application domain and ultimately determine the optimality or usefulness of the locations computed for placement of sensors (Hart and Murray, 2010).

In the context of hydrological networks, previous sensor placement studies have focused on finding the locations of monitoring devices that would optimally observe the quality of drinking water and detect contaminants introduced accidentally or maliciously (Berry et al., 2003; 2006; Comboul and Ghanem, 2012; Hart and Murray, 2010; Kessler et al., 1998; Preis et al., 2011). On the other hand, studies in sensor networks for purpose of flood monitoring are generally sparse and tend to focus on the design of the system architecture, without any direction on how to optimise the placement of the sensors (Basha et al., 2008; Castillo-Effer et al., 2004; Hughes et al., 2006; Smith et al., 2009).

In this study, the focus is on developing a methodology for finding optimal locations for the placement of a limited number of water-level sensors, such that the acquired water height data are most relevant for facilitating informed and efficient decisions about the operations and management of the flood control infrastructure in different parts of a coastal city. The proposed methodology entails defining a set of optimisation objectives and constraint, which are quantitatively assessed at each potential sensor location. This computation is done through the construction and topological/connectivity analysis of a graph-based network model of the city-wide hydrological infrastructure system. The computed values are then utilised in an optimisation algorithm to determine the optimal locations for the placement of a limited number of sensors. For this optimisation problem, the non-dominated sorting genetic algorithm (NSGA-II), 
a prominent multi-objective optimisation that is based on evolutionary algorithms (EAs) is explored (Deb et al., 2002). NSGA-II is considered appropriate for this study for two reasons. First, NSGA-II has been demonstrated through many real-world applications to be more efficient in terms of computational time and solution quality as compared to classic/analytical optimization algorithms such as linear programming (LP) and dynamic programming (DP) (Fang et al., 2008; Preis and Ostfeld, 2008; Tran, 2009; Zhou et al., 2011). Secondly, NSGA-II uses the concept of paretodominance to handle multi-objective optimisation problems without the need for pre-existing knowledge of the appropriate weighting factors (Parrott et al., 2005).

The methodology is applied to compute new locations for water-level sensors in one of the most exemplary coastal mega-cities situated in developing nations - Jakarta, Indonesia. The results obtained are validated as reliable by domain experts in the city of Jakarta and then used to deploy new sensors in the city's hydrological infrastructure network. It is envisaged that the proposed methodology will be useful in optimally selecting locations for new sensors in other coastal cities that depend heavily on manually operated flood control infrastructure. The next section elaborates on the proposed methodology and in section 3 its application is demonstrated in a case study involving the deployment of new water-level sensors in the city of Jakarta. Section 4 presents the results of the case study application and the discussions of these results and their implications are also provided in this section. Finally, section 5 concludes the article, highlights key limitations and makes recommendation for future research.

\section{Methods}

Water-level sensors monitor river heights and report back real-time data, which can be utilised to improve operational decisions related to the use of hydrological infrastructure in coastal cities. For example, data from water-level sensors can be used for deciding on whether to switch on or switch off a pumping station or whether to open or close a floodgate. In this section, methods development is presented that can be applied in finding optimal locations for the placement of a limited number of water-level sensors in a city-wide hydrological infrastructure network. The sensor placement optimization aims to select locations where water-level data are most useful for optimally operating the different hydrological infrastructure components in various parts of a coastal city. To solve such sensor placement problems, it is important to clearly define the optimization objectives (Hart and Murray, 2010).

\subsection{Formulation of optimisation objectives}

There are several possible objectives that could be formulated for optimal sensor placement, many of which can be classified into three general intents (Berry et al., 2003; Shastri and Diwekar, 2006). The first general objective is to place sensors in locations where they monitor scenarios of high impact (Comboul and Ghanem, 2012). For example, in optimally placing sensors to detect contaminations in drinking water distribution networks, many studies consider 
population density as an objective representing locations of high impact (e.g. Berry et al., 2005; Krause et al., 2006; 2008b). However, in most coastal mega-cities situated in developing nations, population density tends to be uniformly high across most parts of the city, with many of the most vulnerable population, i.e., the urban poor, having to live in slums or informal settlements that are often not considered when planning flood mitigation measures (Li, 2003). Worse still, the lack of relevant and comprehensive data hinders the reliance on socio-economic factors (e.g., number of people likely to be affected, estimated value of urban property, etc.) as measures for assessing high impact flood zones (Brecht et al., 2012). Given the high settlement density in most coastal mega-cities situated in developing nations, this study assumes that an inundation that occurs in any given location within the city would likely have high impact on people and urban property; hence the aim is to minimise the occurrence of flooding by ensuring that operators of key assets used for flood control (e.g., pumping stations and floodgates) are equipped with relevant information to make optimal decisions in real-time. In this study, locations of high impact are therefore considered to be areas where the density of hydrological infrastructure (e.g., pumping stations and floodgates) is high. The rationale is that the greater the number of hydrological infrastructure assets available in an area to control flood, the higher the likelihood of minimising flood impacts on people, provided operational decisions are made in an informed manner. An important objective in placing the sensors is therefore to gain maximum information about water levels in areas with high numbers of pumping stations and floodgates, so that operators of these flood control infrastructure are better informed to make real-time operational decisions that result in optimal outcomes and minimal flood impact on people. This study therefore uses the infrastructure density at a given location i.e. the number of hydrological infrastructure (e.g. pumping stations and floodgates) located within a unit length of waterways flowing upstream and downstream to that location as an objective for optimal placement of sensors. For each potential sensor location, $v$ in the network, the infrastructure density, $\rho_{v}$ can be represented mathematically with Eq. 1, where $n_{v}^{u}$ is the number of hydrological infrastructure components located within a fixed distance, $\mathrm{k}$ upstream of $v$ and $n_{v}^{d}$ is the number of hydrological infrastructure components located within a fixed distance, $\mathrm{k}$ downstream of $v$. It is worth noting that $\mathrm{k}$ is simply a constant distance (say between $1.0-1.5 \mathrm{~km}$ ) that is used to determine the number of hydrological infrastructure components located within the vicinity, both upstream and downstream of different potential sensor locations being accessed in the network.

$\rho_{v}=n_{v}^{u}+n_{v}^{d}$

The second general objective is to place sensors in locations of high risk of the phenomenon being monitored (Eliades et al., 2013; Southworth, 2008; Weickgenannt et al., 2010). This approach saves time to detect the phenomenon of concern and it is often an important objective for many sensor placement optimisation problems (Ostfeld et al., 2008; $\mathrm{Xu}$ et al., 2008; Wu and Walski, 2006). In the context of this study, the size or classification of waterways is used as an indication of flood risk. In this sense, large rivers with high flow rates are considered as greater sources of fluvial flood risk compared to smaller waterways such as streams. Hence, this study uses the size or classification of waterway, $\mathrm{c}_{v}$ as 
an objective for optimal placement of sensors in the hydrological infrastructure network. Following the classification scheme proposed in Ogie et al. (2017), waterways were classified into four categories, namely very large waterway (flow rate $\geq 550 \mathrm{~m}^{3} / \mathrm{s}$ ), large waterway (flow rate $<550 \mathrm{~m}^{3} / \mathrm{s}$ and $>100 \mathrm{~m}^{3} / \mathrm{s}$ ), small waterway (flow rate $\leq 100 \mathrm{~m}^{3} / \mathrm{s}$ ), and very small waterway (all other smaller watercourses and ditches).

The third general objective is to place sensors in locations that maximise network coverage (Lee and Deininger, 1992; Younis and Akkaya, 2008). Here, the network coverage, net $v_{v}$ at a potential sensor location, $v$ is a measure of the number of waterway segments within the entire network that could be monitored by installing a water-level gauge at that node. In a directional network (e.g. drainage system), an optimal selection of sensor locations based on network coverage objective will tend to favour nodes in which monitoring stations could account for flows from a higher number of upstream channels. To carry out optimisation on the basis of this objective, an understanding of the topology of flow in the network is required and could be attained through topological/connectivity analysis, often based on graph theory (Hart and Murray, 2010; Lee and Deininger, 1992; Perelman and Ostfeld, 2011). Graph theory allows a water network to be modelled as a directed graph, $G=(V, E)$, where $E$ is a set of edges representing waterways (e.g. rivers, canals, streams, etc.) and $V$ is a set of vertices or nodes representing possible locations for the sensors (e.g. river junctions or points where a pump or floodgate exists) (Berger-Wolf et al. 2005; Berry et al. 2005; Kessler et al., 1998). Using the concept of in-degree in graph theory, it is possible to compute the total number of all upstream sources, which could possibly contribute to the flow of water monitored at a given node (Treml et al., 2008). The in-degree of a node is the number of waterway channels (directly) connecting to the node from upstream sources (Treml et al., 2008). By simply taking the sum of the in-degree, $\mathrm{deg}^{-}$of all upstream nodes connected to a given node, $v$, the network coverage, net $_{v}$ at that node can be computed using Eq. 2, where it is assumed that the number of upstream nodes can range from 0 to $n$.

$n e t_{v}=\sum_{i=0}^{n} \operatorname{deg}^{-}(v)$

For example, the network coverage, net $_{v}$ of each node in the hypothetical directional graph shown in Fig. 1 is as follows: $\mathrm{A}=0, \mathrm{~B}=0, \mathrm{C}=0, \mathrm{D}=2, \mathrm{E}=4$ and $\mathrm{F}=5$. This means that sensor placement in locations $\mathrm{A}, \mathrm{B}$, or $\mathrm{C}$ could monitor flows in $0 \%$ of the network channels, D could monitor $40 \%$, E could monitor $80 \%$ while F could $100 \%$ of the network channels. The results show that the use of network coverage, net $_{v}$ as an optimisation objective tends to favour locations located far downstream. This lopsided effect towards downstream locations must therefore be balanced out in combination with other optimisation objectives by using appropriate weighting factors (Comboul and Ghanem, 2012). 


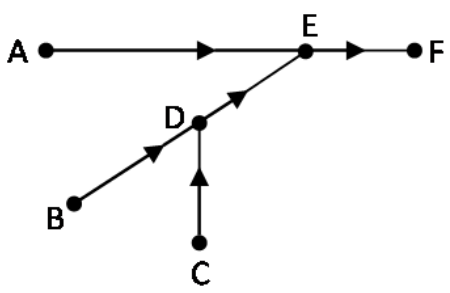

Fig. 1. Directional graph

However, choosing appropriate weightings for different optimisation objectives remains a complex problem that is subject to the understanding of the relative importance of each objective against the others (Krause et al. 2006). This study combines the three aforementioned optimisation objectives in an objective function, $f_{1}(v)$ using weighting factors (see Eq. 3) that are based on consultation and advice from at least three domain experts in hydrology, flood risk and emergency services, having good knowledge of the study area. The selected experts were chosen based on their experience, knowledge and reputation in the field of interest.

$f_{1}(v)=0.7 \rho_{v}+0.2 c_{v}+0.1$ et $_{v}$

By substituting Eq. 1 and Eq. 2 into Eq. 3, Eq. 4 is obtained for computing $f_{1}(v)$.

$f_{1}(v)=0.7\left(n_{v}^{u}+n_{v}^{d}\right)+0.2 \mathrm{c}_{v}+0.1 \sum_{i=0}^{n} \operatorname{deg}^{-}(v)$

Let us consider that there are $n$ sensors to be placed in the network and set of potential sensor locations is represented by $S$, so that $S=\left(s_{1}, S_{2}, S_{3} \ldots, s_{n}\right)$. Then, the overall objective function value, represented as $F_{1}(S)$ is computed by adding $f_{1}(v)$ values for each location, $v \in S$. This is represented mathematically in Eq. 5 .

$$
\text { Maximise: } F_{1}(S)=\sum_{v \in S} f_{1}(v)
$$

Furthermore, to avoid sensor placements in close proximity to each other, an objective function $f_{2}(v)$ is introduced in Eq. 6.

$$
f_{2}(v)=\sum_{u \in S} d_{(v, u)}
$$

where, $d_{(v, u)}$ is the geographic distance from a potential sensor location, $v$ to another potential sensor location, $u$ and $(v, u) \in S$. Similarly, $F_{2}(S)$ represents the overall distance between candidate sensor locations. Therefore,

$$
\text { Maximise: } F_{2}(S)=\sum_{v \in S} \sum_{u \in S} d_{(v, u)}=\sum_{v \in S} f_{2}(v)
$$

Likewise, a constraint is introduced to restrict the placement of sensors near locations where flood gauges already exist. This constraint is represented by Eq. 8 . 


$$
d_{(v, t)}^{e}>\lambda \quad \forall v \in S, t \in T
$$

In Eq. $8, d_{(v, t)}^{e}$ represents the distance from a potential sensor location, $v$ to an existing sensor location, $t$, where $T$ is a set of all existing sensor locations, $S$ is a set of all potential sensor locations and $\lambda$ is the minimum distance at which a potential sensor can be placed from an existing sensor.

When $F_{1}, F_{2}$ is used as objective functions, a set of Pareto optimal solutions are identified, which provides us with a better idea about the range of spatial coverage and impact that can be achieved. A decision maker can then select appropriate solution from the Pareto set based on their preferences. A predefined threshold for spatial coverage can be defined if $F_{2}$ is to be used as a constraint while having $F_{1}$ as a single objective. However, determining appropriate threshold and generalising it over several instances of sensor placement can be difficult in real practice. Therefore, we have used $F_{2}$ as an objective function so that the formulation can be generalised for other instances of sensor placement problem. We state that the proposed formulation can also be formulated into single objective optimisation, depending upon need and in cases where information about the spatial coverage constraint is readily available.

Using Eq. 5 and Eq. 7, $F_{1}(S)$ and $F_{2}(S)$ are computed for each set of sensor locations in the network. These functions are used in a multi-objective optimisation algorithm to determine the optimal locations for a pre-defined number of potential sensors. The optimisation algorithm which aims to maximise $F_{1}(S)$ and $F_{2}(S)$, i.e., select locations that have the highest values of $F_{1}(S)$ and $F_{2}(S)$ is presented in the next subsection.

\subsection{Non-dominated sorting genetic algorithm (NSGA-II)}

In last decade, researchers in the area of soft computing have often applied multi-objective evolutionary algorithms which use mechanisms inspired by biological evolution, reproduction, mutation, recombination and selection for efficiently optimising complex optimisation problems. As such, they attempt to simulate natural phenomena to find solution to hard optimisation problems. Among others, the most prominent multi-objective optimisation is the Nondominated sorting genetic algorithm (NSGA-II) (Deb et al. 2002). It has been used widely for solving multi-objective problems (Atiquzzaman et al., 2006; Chang and Chang, 2009; Gonçalves et al., 2016; Tadeu et al., 2016; Zhou et al., 2011).

NSGA-II is based on the concepts of Pareto-front and non-domination. Pareto-front is a locus formed by the set of solutions that are equally good when compared to other solutions for a multi-objective optimisation problem. Nondominated solutions, on the other hand, refer to the solutions in the set which do not dominate each other, i.e., no solution is better than the other when all the objective functions are evaluated. 
Fig. 2 illustrates the overall steps involved in the NSGA-II algorithm. It starts with a set of initial solutions, representing sensor locations in the network, aka initial population. Here, each solution can be interpreted as set $S$, defined in Section 2.1. $F_{1}$ and $F_{2}$ values for each of these solutions are evaluated to rank solutions based on a sorting algorithm known as Pareto-fast non-dominated (PF-ND) algorithm (see Deb et al. 2002 for details). Then, based on some stopping criteria (e.g. maximum number of generations), genetic operators are applied. These operators are (i) selection of parents (solutions) from the population, (ii) crossover to generate children (solutions) from parents, (iii) mutate children, and (iv) elitism to select population for next generation. In elitism, population and children are combined together and are ranked according to the PR-ND sorting. These ranks are used to select a population that is passed on to the next generation. These steps (i-iv) are iterated until maximum number of generation is achieved. Finally, the solutions representing Pareto-optimal front is generated at the end of the iterations.

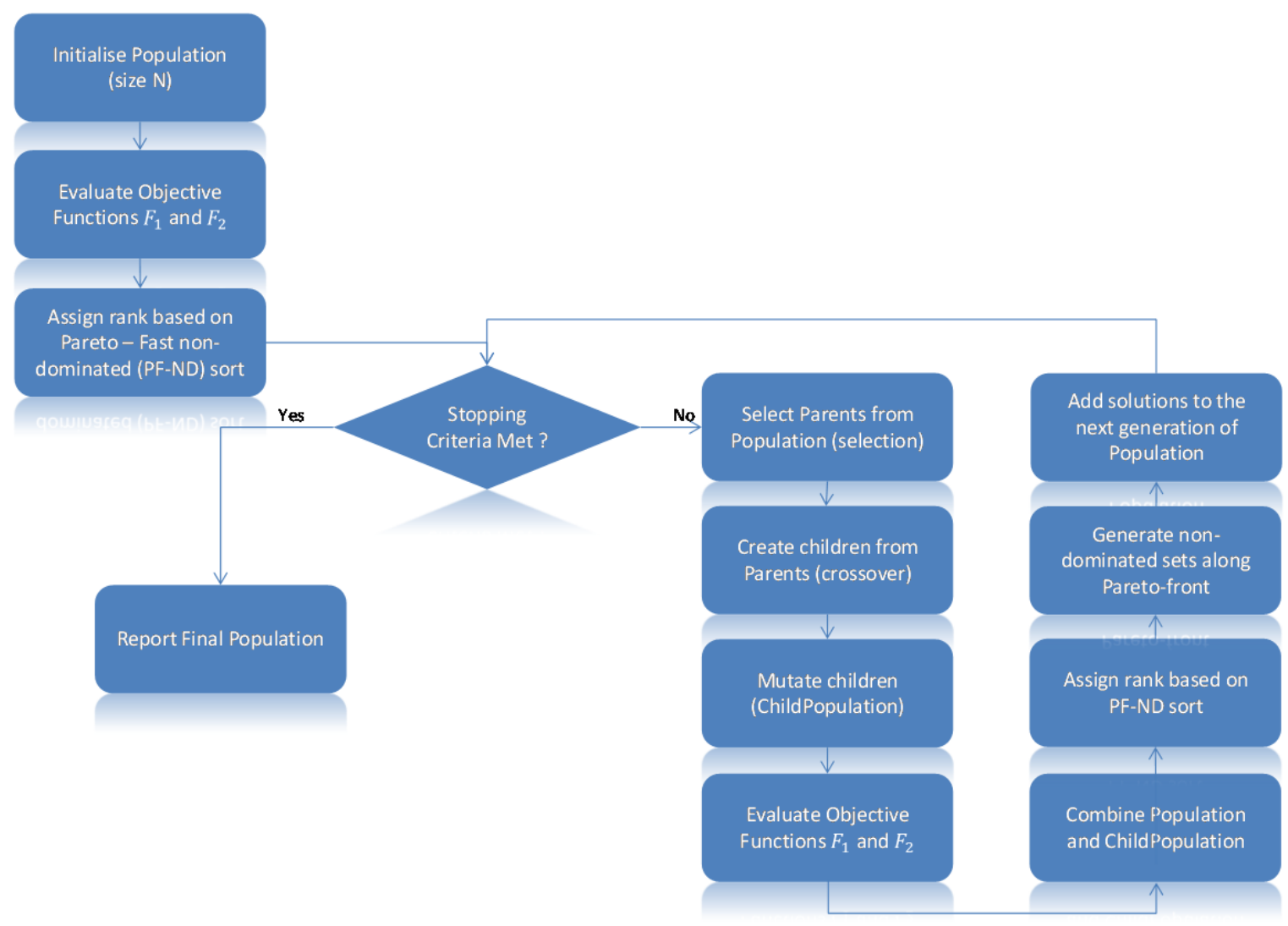

Fig. 2. Overall steps involved in the NSGA-II algorithm

\section{Case study application: Jakarta, Indonesia}

Jakarta, the capital of Indonesia, is a low-lying coastal conurbation of over 14 million people and 2.5 million daily commuters from the adjacent cities (Takagi et al., 2016). The city is one of the most rapidly urbanising and densely populated coastal mega-cities situated in the developing nations of the world (Li, 2003). Jakarta occupies approximately 
$662 \mathrm{~km} 2$ of land area and contains a large waterway network of 13 naturally occurring rivers and hundreds of manmade drainage canals (Ogie et al., 2017; World Bank, 2010). Every year, the citizens of Jakarta are exposed to the damaging impacts of monsoonal floods, which typically occur between the months of November and March (Ogie et al., 2016). In response to the problem of flooding, Jakarta relies on a network of hydrological infrastructure assets to monitor and control the flow of water from surrounding hills and mountains, through the city to the Java Sea in the north (Hartono et al., 2010). These hydrological infrastructure assets include water-level gauges, drainage channels or waterways, pumping stations, floodgates, etc. (Caljouw et al., 2005; Ogie et al., 2016). Fig. 3 shows the locations of these hydrological infrastructure assets in the city of Jakarta.

The efficient management of these hydrological infrastructure assets during flooding events is crucial for optimal flood control outcomes and often dependent on availability of city-wide, real-time accurate water-level data to improve operational decisions (Ogie et al., 2016; Pleau et al., 2005). Admittedly, the current situation in which the Jakarta government relies on just 11 known functional water-level gauges to monitor a complex network of approximately 1092 $\mathrm{km}$ length of waterways, in order to manage flood conditions using 71 pumping stations and 30 manually operated floodgates is grossly inadequate for achieving the desired level of efficiency (Ogie et al., 2016). The result is poor flood control outcomes and failure of the aging hydrological infrastructure system, often leading to inundation that have devastating impact on the people, property, economy, and environment (Brinkman and Hartman, 2008; Few, 2003; Ward et al., 2011). The World Bank (2010) estimated the annual cost of flood damage in Jakarta to be over USD 400 million. This level of loss calls for more innovative and data-driven approaches to managing hydrological infrastructure assets in order to improve monitoring and control of water flow. The need for such data-driven management of the hydrological infrastructure assets has also been emphasised in a recent study establishing the linkage between Jakarta's floods and the failing flood control infrastructure (Sedlar, 2016).

In the current study, it is presumed that the introduction of additional monitoring devices such as water-level sensors will facilitate the data-driven management of Jakarta's hydrological infrastructure assets, thus improving flood control outcomes. Given the size and complexity of Jakarta's waterway network and the fact that only a limited number of water-level sensors can be afforded at a time, it becomes very important that the locations for the placement of such sensors be strategically selected in order to attain optimal outcomes in the data-driven approach to hydrological infrastructure asset management. To achieve this aim, a methodology for optimal placement of monitoring devices in a city-wide hydrological infrastructure network is proposed and applied to install new water-level sensors in the city Jakarta. The processes involved in the application are discussed in the following subsections. 


\subsection{Network construction and analysis}

Prior to applying the optimisation algorithm for sensor placement, a spatio-topological graph-based network of Jakarta's hydrological infrastructure system was constructed. Topological/connectivity analysis of the network is required to generate relevant data for the algorithmic computation of optimal sensor locations. For the purpose of constructing the network, data regarding Jakarta's hydrological infrastructure assets were acquired through ground survey, GPS locations and aerial imagery analysis. The acquired spatial vector data comprise the name, location and capacity of both the hydraulic components (e.g. pumping stations, floodgates, and flood gauges) and the waterways or hydrological components (e.g. rivers, canals, and streams). The output from the hydraulic component is a point vector file comprising 71 pumping stations, 30 floodgates and 11 flood gauges while the waterway component is a line vector file consisting of 209 rows (Turpin and Holderness, 2015a; 2015b). For ease of data management and analysis, the acquired datasets were stored in spatial database tables within the PostgreSQL and PostGIS Relational Database Management System (Obe and Hsu, 2015).

Before utilising the acquired data for network construction, locational and topological errors were removed using the toolset for cleaning topology of vector map, known as "v.clean.snap" within the GRASS plugin in the Quantum GIS (Geographical Information System) software (Neteler et al., 2012). Furthermore, when a line segment in the waterways vector file intersects with another line or a point feature (i.e., pumping station, floodgate or floodgate), the line is programmatically split into separate line features. This line splitting ensures that when the network is finally constructed, junctions are created where they should exist.

The construction of Jakarta's hydrological infrastructure network was carried out using open-source software developed by Newcastle University and described broadly by Barr et al. (2012). The software provides an integrated environment for the PostGIS spatial relational database and the Python interface to the NetworkX graph analysis package, making it possible to construct and store graph-based networks with encoded spatio-topological configurations (Barr et al., 2012). To accommodate the topology of Jakarta's waterways, in which two separate watercourses are often found to flow from the same source node to the same target node, the network was modelled as a directed multigraph, also known as multidigraph, $G$ (Ogie et al., 2016). Mathematically, $G=(V, E)$, where $V$ is a set of points or nodes that are connected by a set of lines or edges, $E$ to create a graph-based network, $G$ (Biwas et al., 2013). In the graph-based network model of Jakarta's hydrological infrastructure system, the nodes or points are the pumping stations, floodgates and flood gauges while the edges or lines are the waterways, i.e., rivers, canals and streams. Direction of water flow was inferred using public domain, 30m resolution digital elevation data of the Shuttle Radar Topography Mission (SRTM) (USGS, 2015). The accuracy was validated and further improved based on a combination of expert knowledge of the study area and actual field observations of water flow in the city of Jakarta. On completion, the constructed network comprised of 
647 edges representing Jakarta's waterways, with a total geometric length of $1092 \mathrm{~km}$. The nodes were 579, of which

71 were pumping stations, 30 were floodgates, 11 were flood gauges and the remainder represented network junctions such as river confluences. Fig. 3 is a cartographical representation of the constructed network.

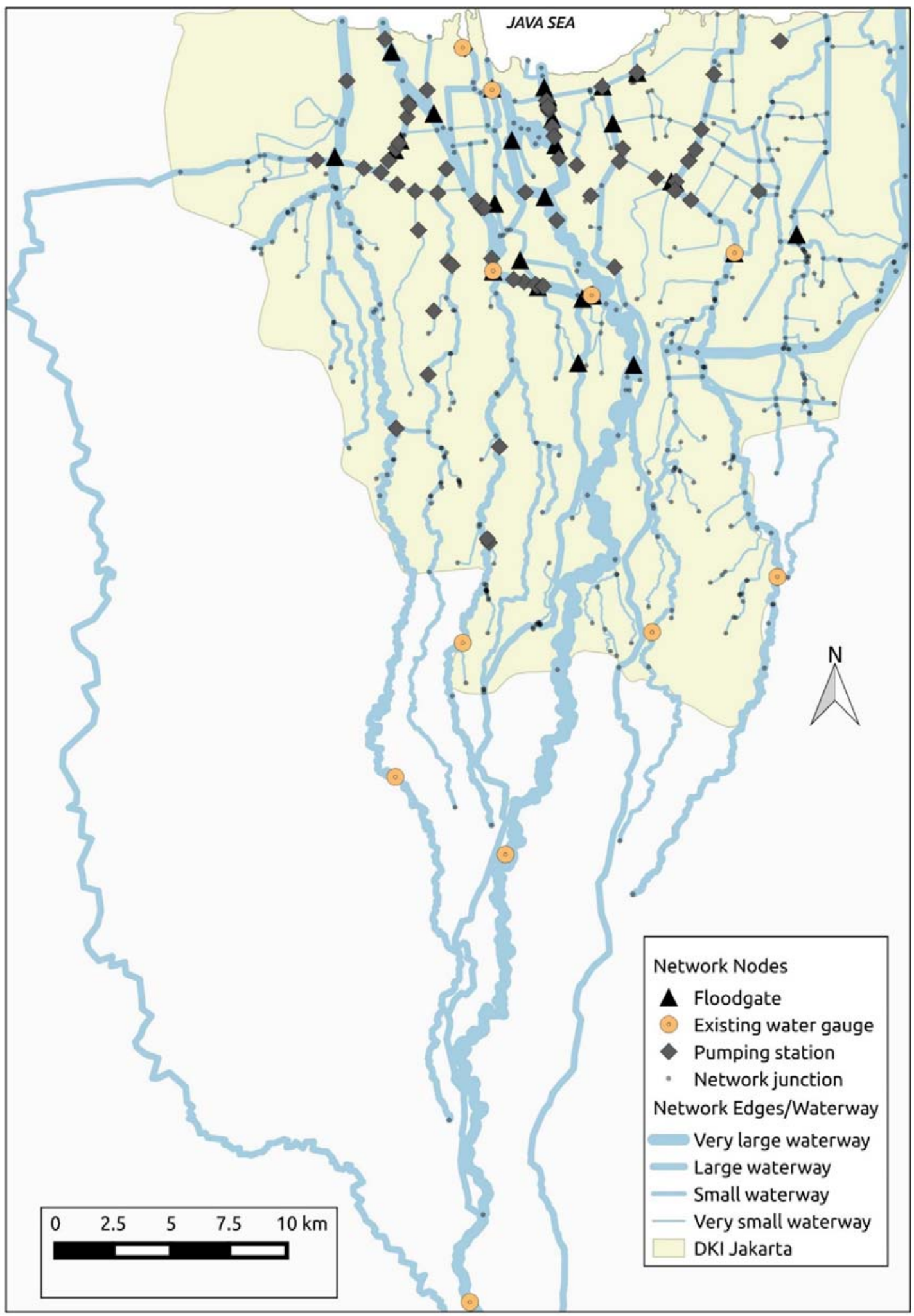

Fig. 3. Graph-based network model of Jakarta's hydrological infrastructure system 
Following the successful construction of the network model, the NetworkX and the Pandas Python libraries (Schult and Swart, 2008) were used in computing the infrastructure density, $\rho_{v}$ based on Eq. 1, the network coverage, net $t_{v}$ based on Eq. 2 and the size or classification of waterway, $c_{v}$ for each potential sensor location in the hydrological network. Potential sensor locations were identified as nodes where infrastructure such as pumping station, floodgate or flood gauge exists. This implies a total of 102 potential sensor locations. Based on the computed values of $\rho_{v}, \mathrm{c}_{v}$ and $n e t_{v}$, Eq. 4 was applied to derive values of $f_{1}(v)$ for each potential sensor location in the network. The derived values of $f_{1}(v)$ are required for computing $F_{1}(S)$ (see Eq. 5) when applying the NSGA-II algorithm for determining optimal locations for sensor placement.

Further analysis of the constructed network involves the use of the NetworkX python library in computing the values of $d_{(v, u)}$, i.e., the geographic distance from a potential sensor location, $v$ to another potential sensor location, $u$. These values are required to parameterise Eq. 7. Similarly, the geographic distance between any given potential sensor location and each existing water-level gauge was computed because these values are required to enforce the sensor placement constraint represented in Eq. 8. All computed values were stored in a PostGIS database table to be readily utilised by the NSGA-II sensor placement algorithm.

\subsection{Sensor placement using the non-dominated sorting genetic algorithm (NSGA-II)}

The application of the sensor placement algorithm to Jakarta's hydrological infrastructure network was implemented in two phases. The first phase involves the real-world deployment of four proof-of-concept water-level sensors developed locally at the Internet of Things (IoT) Hub of the Smart Infrastructure Facility, University of Wollongong, Australia. The technical details behind the development of these ultrasonic water level sensors, including hardware and software configurations are beyond the scope of this paper and will be covered in a separate study. Here, the focus is on optimising the placement of the sensors to facilitate data-driven management (e.g. operational decisions based on rising water level) of city-wide flood control infrastructure. To compute optimal locations for placement of sensor, the nondominated sorting genetic algorithm (NSGA-II) was applied within the MATLAB programming environment. Based on the spatial distribution of Jakarta's existing monitoring stations, the minimum distance, $\lambda$ at which a potential sensor can be placed from an existing water-level gauge, was chosen to be $5 \mathrm{~km}$. This application generated a set of solutions with different optimal configurations, from which the decision maker is expected to select one for actual deployment. In utilising the generated solution for actual field deployment of the sensors, the feasibility of installing and maintaining sensors at the recommended locations was taken into consideration. Key factors considered include accessibility to recommended sensor locations within the waterway, availability of physical structure to mount the sensor, sufficient space to accommodate a metal cage for locking up and protecting the sensor from theft, cell signal quality, and the 
requirement to place sensors at safe height above water-level, which may rise up to $3 \mathrm{~m}$ in a 12 hour period of extensive monsoonal rain as observed with data from PetaJakarta.org (Holderness and Turpin, 2015). With these considerations in mind, appropriate locations not more than $10 \mathrm{~m}$ away from the computed optimal locations were scouted and the sensors physically installed in August, 2016.

In the second phase of the application, the sensor placement algorithm was applied to recommend the next set of optimal locations for the Jakarta government to deploy additional water-level sensors as resources permit in the future. Taking the newly deployed 4 sensors into consideration, this application computes the next most optimal locations for future deployment of additional 10 sensors. First, the locations of the 4 sensors were integrated into the network, giving rise to a reconstructed graph of 583 nodes and 651 edges. The same algorithmic process followed to compute the locations of the 4 sensors was adopted to recommend optimal locations for the additional 10 future sensors. However, given that the density of monitoring stations have slightly increased with the initial installation of 4 water-level sensors, the value of $\lambda$ used in the algorithmic computational process was reduced from $5 \mathrm{~km}$ to $3 \mathrm{~km}$ so that more sensor locations can be explored in the optimisation procedure. Recall that $\lambda$ is the minimum distance at which a potential sensor can be placed from an existing sensor. The results are presented in the following section.

\section{Results and discussions}

The results of the application of the sensor placement methodology to Jakarta's hydrological infrastructure network are presented and their implications discussed in this section. For the first phase of the application that involves 4 waterlevel sensors, the NSGA-II based solutions are shown in Fig. 4. Given that NSGA-II uses random base structure, multiple fronts were obtained after 100 runs of the algorithm as shown in Fig. 4. The final Pareto-front is nominated by selecting the non-dominated best solutions (see Fig. 4), which represents the best feasible of both objectives at a time. The final locations selected for deploying the 4 sensors are shown cartographically in Fig. 5. Basically, Sensors 1, 2, 3 and 4 were installed in the West Flood Canal near the Karet train station, the Sunter Canal near Kelapa Gading, the Ciliwung River near Mangga Dua Square, and the Kali Mookevart canal near the Poglar floodgate respectively. These results demonstrate the usefulness of the proposed methodology in recommending optimal sensor locations, which achieve several objectives and constraint that would otherwise be difficult to attain manually for a city-scale network. More specifically, the proposed methodology has been demonstrated to be useful in achieving optimal placement of water-level sensors at locations that are: (1) situated in areas of high infrastructure density, i.e., locations where the number of hydrological infrastructure (e.g. pumping stations and floodgates) within a unit length of waterways flowing upstream and downstream to the given location are highest; (2) located in large river reaches or areas of high flood risks; (3) located in areas that maximise network coverage, i.e., locations that account for flow in maximum number of river segments in the network; (4) located furthest away from existing water gauges to improve spatial coverage of the 
network; and (5) located furthest away from other potential sensor locations to avoid crowding the new sensors within the same vicinity.

Fig. 5 further illustrates these results. For example, the location for Sensor 1 was selected because it is situated on a "very large waterway" that is more likely to pose high flood risk and there is also a high density of infrastructure (i.e., pumping stations and floodgates) within $1.5 \mathrm{~km}$ upstream and downstream to the selected location. More specifically, there are 6 connected upstream infrastructure located at $0.47 \mathrm{~km}, 0.97 \mathrm{~km}, 1.11 \mathrm{~km}, 1.17 \mathrm{~km}, 1.30 \mathrm{~km}$ and $1.32 \mathrm{~km}$ to the selected location for Sensor 1. Similarly, within $1.5 \mathrm{~km}$ downstream of Sensor 1, there are 3 infrastructure located at distances of $0.97 \mathrm{~km}, 1 \mathrm{~km}$ and $1.02 \mathrm{~km}$. Water-level data generated by sensor 1 can enable flood control operators make time-critical decisions on when to open or close the floodgates and when to turn on or turn off the pumps. Generally, when water-level data from a sensor indicates high risk of flooding, the pumps located downstream are turned on to remove accumulating floodwater, thereby increasing the flow of water away from the area under flood risk (Ogie et al., 2016). The upstream floodgates can also be closed in order to divert water from flowing toward the location of high flood risk (Ogie et al., 2016). When network coverage, net $_{v}$ objective is considered, the selected location for Sensor 1 is such that it can only account for water flowing from 7 upstream sources. However, the aforementioned factors, (i.e. infrastructure density and size of river) still make the selected location a high ranking position to place a sensor. The location for Sensor 2 was also selected by the algorithm for similar reasons. There are 4 connected upstream infrastructure located at $1.04 \mathrm{~km}, 1.09 \mathrm{~km}, 1.24 \mathrm{~km}$ and $1.49 \mathrm{~km}$ away from Sensor 2 as well as 3 connected infrastructure located at $0.01 \mathrm{~km}, 0.58 \mathrm{~km}$ and $1.48 \mathrm{~km}$ downstream. Sensor 2 is situated on a "large waterway" and the location in the network is such that it can account for water flowing from 95 upstream sources. These factors put together make the location of Sensor 2 highly ranked for sensor placement. The location of Sensor 3 also ranked high because it is situated on a "very large waterway" and a sensor placed at that network node can account for water flowing from 27 upstream sources. Importantly, there are 5 connected upstream infrastructure located at $0.38 \mathrm{~km}, 0.44 \mathrm{~km}, 0.80 \mathrm{~km}, 1.39 \mathrm{~km}$ and $1.41 \mathrm{~km}$ away from Sensor 3 as well as 6 connected infrastructure located at $0.73 \mathrm{~km}, 0.80 \mathrm{~km}, 0.88 \mathrm{~km}, 1.15 \mathrm{~km}, 1.17 \mathrm{~km}$ and $1.40 \mathrm{~km}$ downstream. For sensor 4 , there are 2 connected infrastructure located upstream at distances of $0.54 \mathrm{~km}$ and $1.19 \mathrm{~km}$ while 3 downstream infrastructure exist at distances of $0.08 \mathrm{~km} 0.34 \mathrm{~km}$ and $0.48 \mathrm{~km}$. Sensor 4 is situated on a "large waterway" and its location in the network will allow it to account for water flowing from 45 upstream sources. While other similarly high ranking locations may exist for sensor placement, the reason for having the selected locations together as a solution set can be better appreciated when other important objectives are also considered, including the need to (i) avoid sensor placements in close proximity to each other and (ii) restrict the placement of sensors near locations with existing flood gauges. 


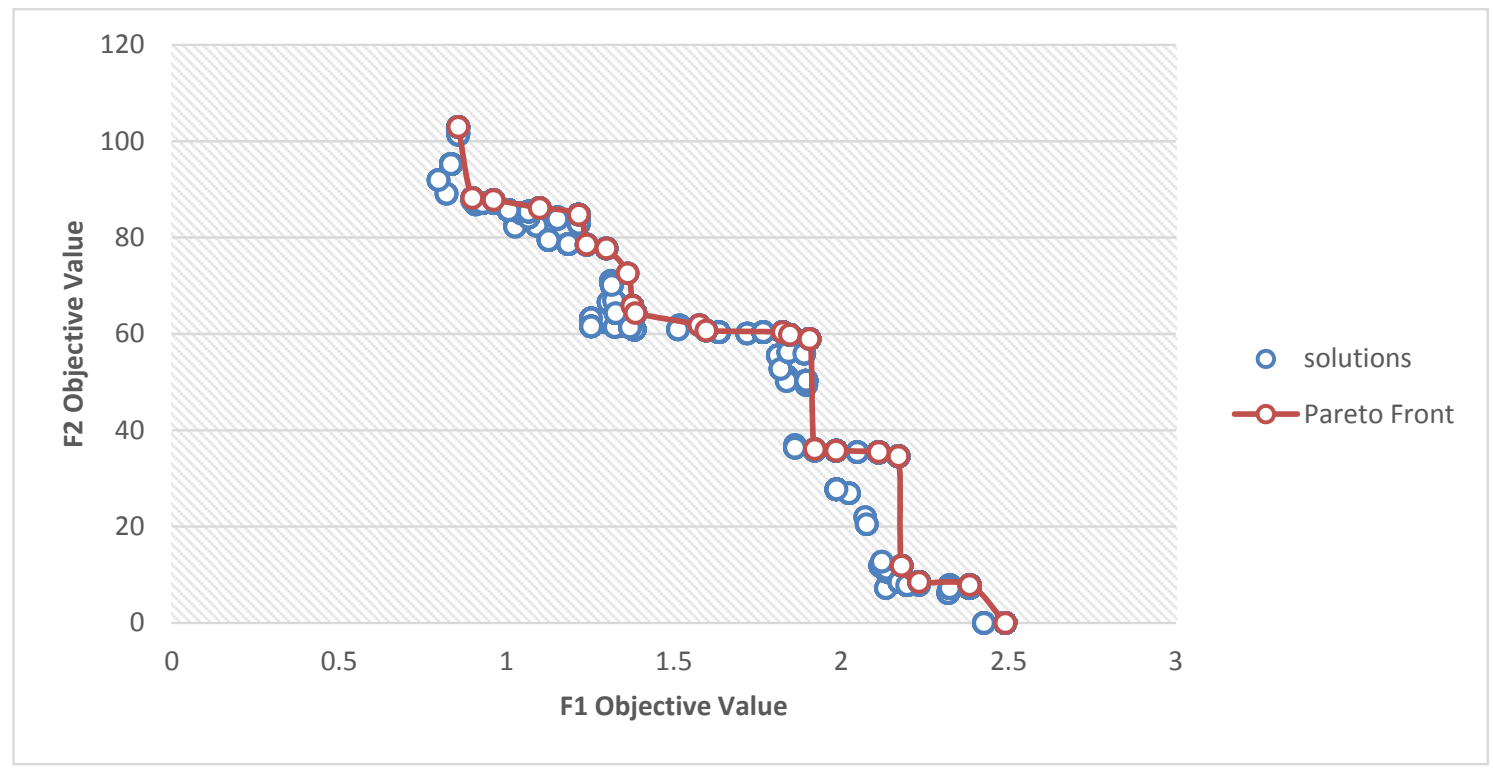

Fig. 4. NSGA-II generated solutions showing Pareto front after 100 runs (4 sensors) 


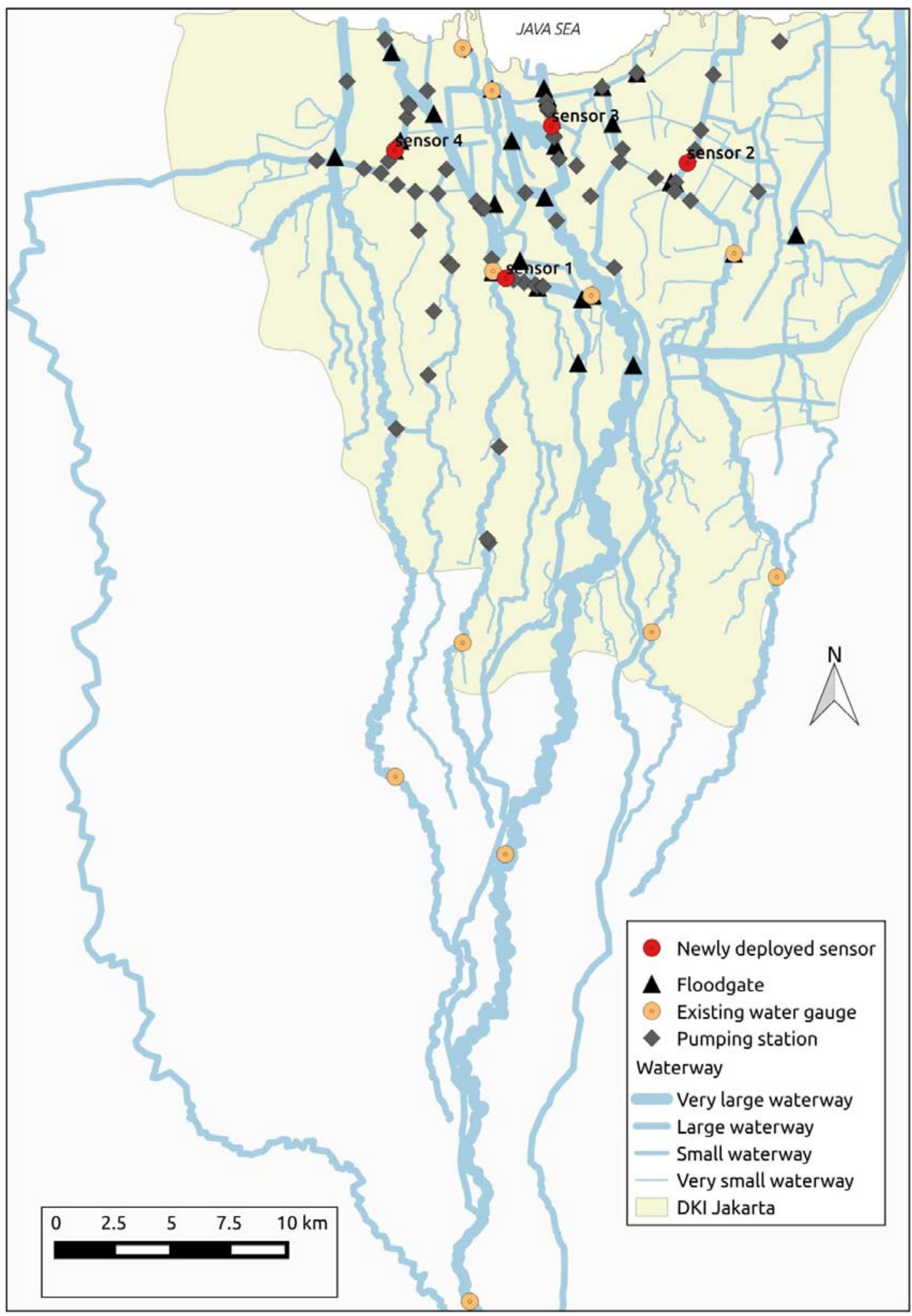

Fig. 5. Showing locations of 4 newly deployed sensors in Jakarta

Furthermore, the results for the second phase of the application that involves 10 sensors are presented in Fig. 6, clearly highlighting the algorithmically generated solution set in the Pareto front. Fig. 6 shows all the Pareto optimal (nondominated) solutions (or Pareto front) set where $\mathrm{X}$-axis and $\mathrm{Y}$-axis represents the $F_{1}$ and $F_{2}$ values. In the proposed 
multi-objective optimisation formulation for sensor placement, both of the objective functions are conflicting, i.e., trade-offs are necessary to make optimal decisions. In this case, there exists a finite set of Pareto optimal solutions (shown in Fig. 6) where none of the objective functions can be improved in value without trading off the other objective function value. The Pareto optimal solutions are considered equally good without subjective preference information from the decision maker.

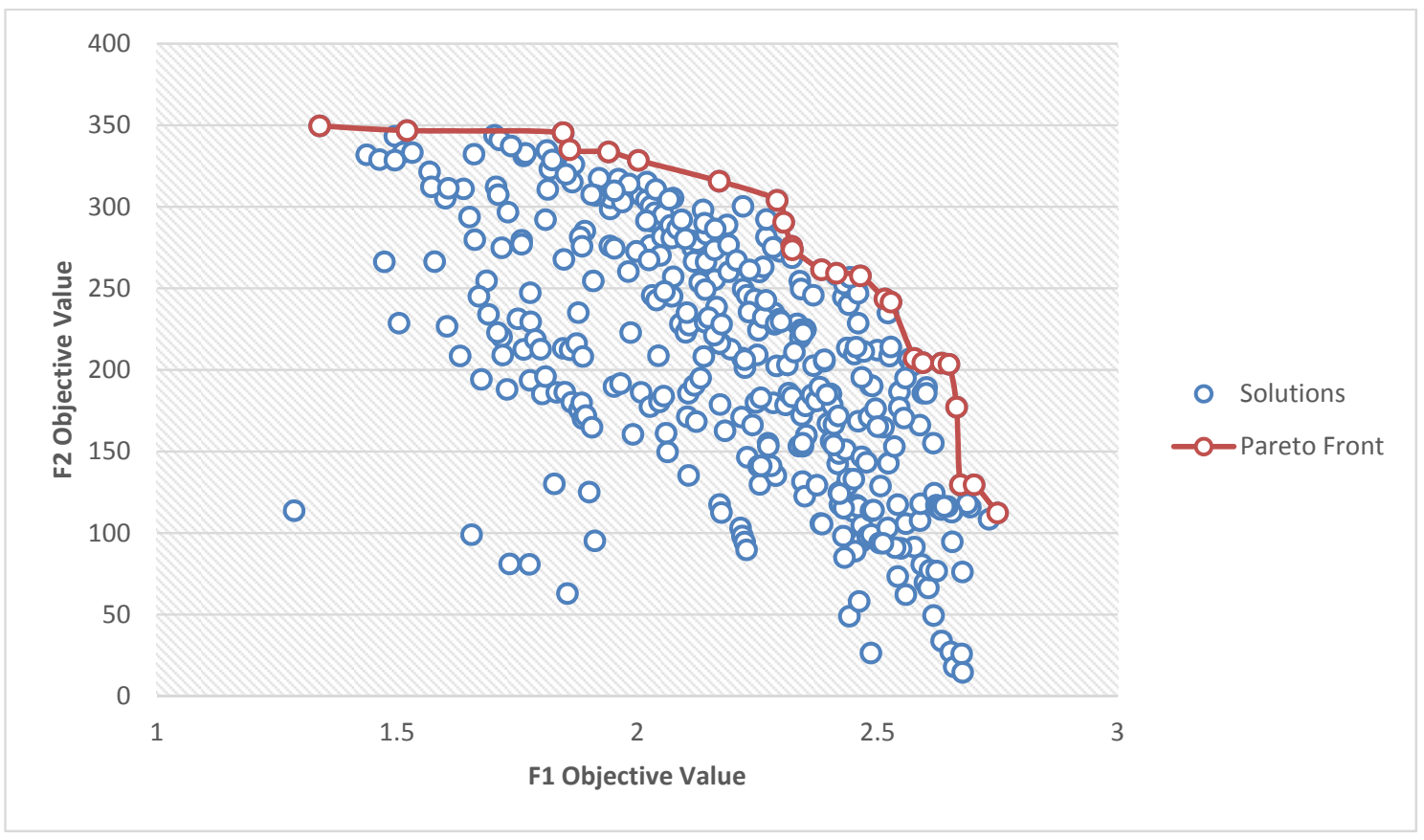

Fig. 6. NSGA-II generated solutions showing Pareto front after 100 runs (10 sensors).

The locations finally selected from the Pareto optimal solutions sets for future placement of additional 10 sensors are shown in Fig. 7. The selected locations represent points in Jakarta's hydrological network where water level data from sensors are most beneficial for improving decisions related to the operations of the different flood control infrastructure situated in various parts of the city. The use of such sensor-fed real-time data of changing water level in coastal megacities of developing nations can facilitate the much needed transition in the management of the hydrological infrastructure assets from a data-starved approach that is characterised by elements of assumptions and suboptimal flood control outcomes to a data-driven strategy that facilitates speedy, accurate, and efficient operational decisions (Saputelli et al., 2006). Essentially, as the locations of water-level sensors are strategically selected for optimal outcomes, the management and operational decisions relating to flood control infrastructure in coastal mega-cities of developing nations can be reliably driven by sensor-detected events (e.g. rising water level) rather than purely on intuition or incomplete situation information. For example, water-level data generated by sensors placed at strategic locations in the hydrological infrastructure network can enable flood control operators make time-critical decisions on when to open or close relevant upstream floodgates and when to turn on or turn off downstream pumps (Ogie et al., 2016). When used 
together with short-term weather forecast data, water-level information from sensors can also enable coastal authorities get better prepared for forthcoming flood events. Over time, the historical data acquired from the water-level sensors becomes a useful resource for other planning and management decisions, including data-driven prediction of flood risks, shoring up of flood barriers in areas of higher risk and priority allocation of limited resources to increase river capacity through the activity of dredging (Georgakakos, 1986). In addition, water-level data from installed sensors, particularly in data-scare regions of developing nations, can help to improve flood inundation models, which are often considered useful for proactive mitigation of flood impacts (Bates, 2004). No doubt, the sensor placement methodology proposed in this study will enable coastal authorities in developing nations improve flood control outcomes in a datadriven approach that efficiently maximises the limited resources available for monitoring and planning. 


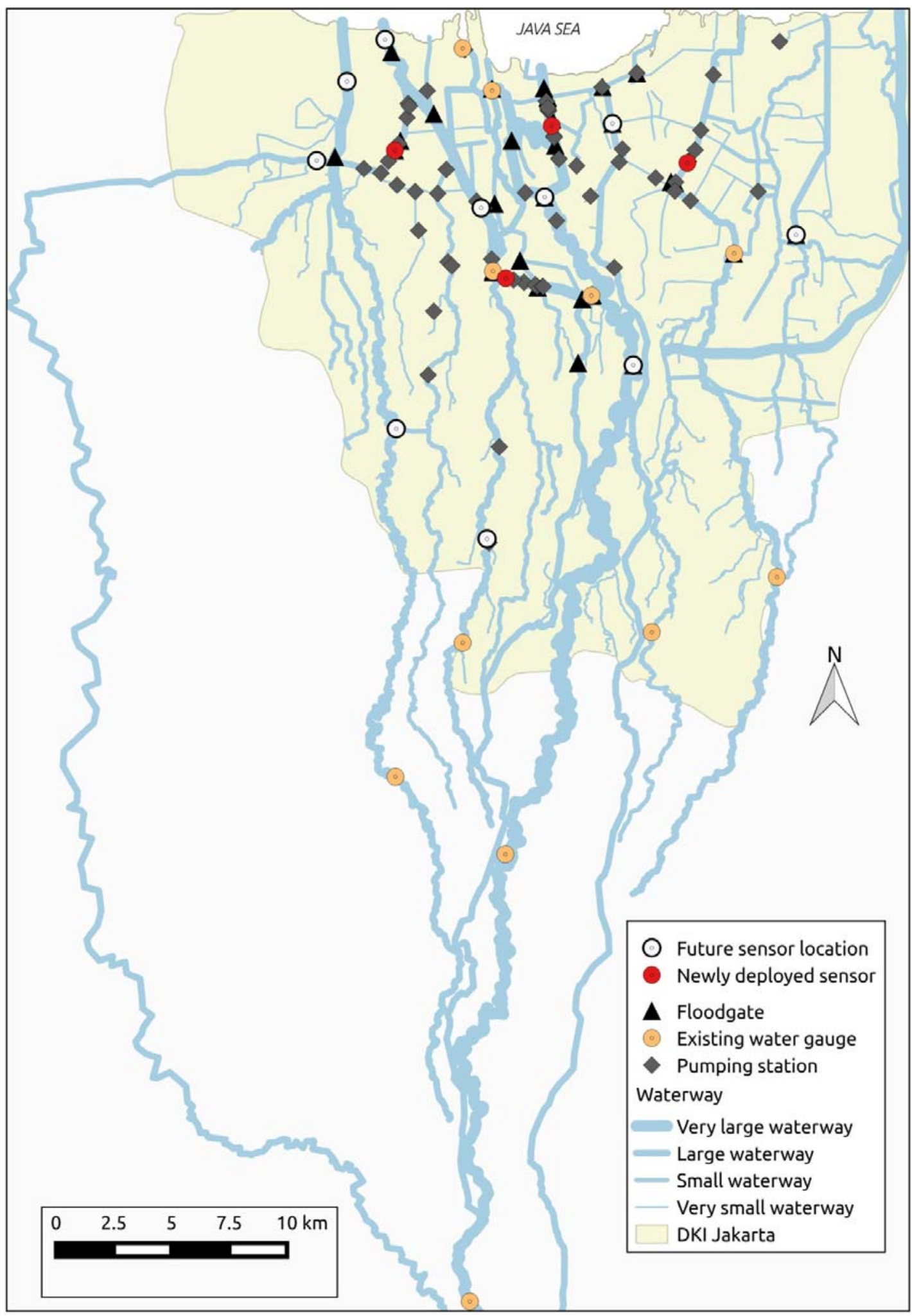

Fig. 7. Optimal locations in Jakarta for future placement of additional 10 sensors

\section{Conclusions}

Flooding is a major problem in coastal urban areas, particularly in developing mega-cities where the resources to monitor river height and respond to flood risks are grossly inadequate. Without adequate information about water levels 
in the rivers flowing through different parts of these cities, it is increasingly difficult to efficiently manage or coordinate the real-time operations of the flood control infrastructure. Suboptimal flood control outcomes are devastating to riverine communities and associated flood losses run into billions of dollars. Water-level sensors provide reliable and accurate data to improve the management and operational decisions related to the use of hydrological infrastructure assets (e.g. pumping stations and floodgates) for flood control in coastal mega-cities. In pursuing this data-driven approach to management of hydrological infrastructure assets, the shortage of resources available to monitor all segments of the waterways means that the limited number of monitoring devices have to be strategically positioned in locations where the acquired water-level data are most beneficial for improving flood control decisions. This study has proposed a methodology for finding optimal locations for the placement of a limited number of water-level sensors, such that the acquired water height data provide maximum benefits for facilitating informed and efficient decisions about the operations of the flood control infrastructure in different parts of a coastal city.

The proposed methodology entails a set of optimisation objectives and constraint, which include the placement of sensors in locations that are: (1) situated in areas of high infrastructure density, i.e., locations where the number of hydrological infrastructure (e.g. pumping stations and floodgates) within a unit length of waterways flowing upstream and downstream to the given location are highest; (2) located in large river reaches or areas of high flood risks; (3) located in areas that maximise network coverage, i.e., locations that account for flows in a maximum number of river segments in the network; (4) located furthest away from existing water gauges to improve spatial coverage of the network; and (5) located furthest away from other potential sensor locations to avoid crowding the new sensors within the same vicinity. These optimisation objectives and constraint were quantitatively assessed at each potential sensor location through the construction and analysis of a graph-based network model of the city-wide hydrological infrastructure system. The computed values were then utilised in a non-dominated sorting genetic algorithm (NSGA-II) to determine the optimal locations for the placement of a limited number of sensors.

The methodology was applied to deploy 4 locally developed water-level sensors into the Jakarta's hydrological infrastructure network. Taking these 4 newly installed sensors into consideration of locations with existing monitoring devices, the algorithm was further applied to compute the next most optimal locations for future deployment of additional 10 sensors. No doubt, the sensor placement methodology proposed in this study will enable coastal authorities in developing nations transition the management of their hydrological infrastructure assets from a datastarved approach that is characterised by elements of assumptions and suboptimal flood control outcomes to a datadriven strategy that facilitates speedy, accurate, and efficient operational decisions. More importantly, the proposed methodology will ensure that as coastal communities embrace data-driven approach to flood control, the limited number 
of sensors fostering the process can be architected to generate the most relevant data for improved decision making by strategically locating them in areas of maximum benefits.

One major limitation of this study is the lack of comprehensive records of the names and locations of (all) the waterlevel monitoring stations in Jakarta. The publicly available dataset indicates that there are 11 known water gauges in Jakarta, all of which are read manually. However, field observation shows that there are more installed sensors maintained by different government agencies in the city of Jakarta, many of which their functional capacities are in doubt. A comprehensive list of the names, locations and functional conditions of these monitoring stations, if available, would further help to improve the usefulness of results obtained from applying the proposed methodology to Jakarta's hydrological infrastructure network. Lastly, it is recommended that future studies seek to improve the robustness of the proposed methodology by understanding how computed optimal locations for sensor placement may change with the consideration of other broader factors such as providing allowance for sensor failures, the use of number of sensors as decision variable in the optimisation process and the use of heterogeneous monitoring devices, including mobile phones in participatory sensing.

\section{Acknowledgements}

This work was supported by the Australian National Data Service (ANDS) through the National Collaborative Research Infrastructure Strategy Program [ANDS MODC 15, 2014], the Department of Foreign Affairs and Trade, Australia (DFAT) [agreement number 71984] and the University of Wollongong Global Challenges Program. The authors thank

Dr. Etienne Turpin for his assistance in obtaining funding and facilitating data gathering for this research, as well as Dr. Matthew Berryman who was one of those that physically installed the sensors in Jakarta's waterways. We also thank everyone who has provided expert advice in designing the proposed solution.

\section{References}

Adenle, A.A., Azadi, H. and Arbiol, J., 2015. Global assessment of technological innovation for climate change adaptation and mitigation in developing world. Journal of environmental management, 161, pp.261-275.

Aitsaadi, N., Achir, N., Boussetta, K. and Pujolle, G., 2009. A tabu search wsn deployment method for monitoring geographically irregular distributed events. Sensors, 9(3), pp.1625-1643.

Akyildiz, I.F., Su, W., Sankarasubramaniam, Y. and Cayirci, E., 2002. A survey on sensor networks. IEEE communications magazine, 40(8), pp.102-114.

Alexander, D., 1991. Information technology in real-time for monitoring and managing natural disasters. Progress in Physical Geography, 15(3), pp.238-260.

Atiquzzaman, M., Liong, S.Y. and Yu, X., 2006. Alternative decision making in water distribution network with NSGA-II. Journal of water resources planning and management, 132(2), pp.122-126.

Barrat, A., Barthelemy, M., Pastor-Satorras, R. and Vespignani, A., 2004. The architecture of complex weighted networks. Proceedings of the National Academy of Sciences of the United States of America,101(11), pp.37473752.

Barr, S.L., Holderness, T., Alderson, D., Robson, C. and Ford, A., 2012. An open source relational database schema and system for the analysis of large scale spatially interdependent infrastructure networks. In 4th Open Source GIS Conference (OSGIS). 
Basha, E.A., Ravela, S. and Rus, D., 2008, November. Model-based monitoring for early warning flood detection. In Proceedings of the 6th ACM conference on Embedded network sensor systems (pp. 295-308). ACM.

Berger-Wolf, T.Y., Hart, W.E. and Saia, J., 2005. Discrete sensor placement problems in distribution networks. Mathematical and Computer Modelling,42(13), pp.1385-1396.

Berry, J., Fleischer, L., Hart, W.E. and Phillips, C., 2003, June. Sensor placement in municipal water networks. In Proceedings of the world water and environmental resources conference. Reston, Va: ASCE.

Berry, J.W., Fleischer, L., Hart, W.E., Phillips, C.A. and Watson, J.P., 2005. Sensor placement in municipal water networks. Journal of Water Resources Planning and Management, 131(3), pp.237-243.

Biswas, S.S., Alam, B. and Doja, M.N., 2013. Generalisation of Dijkstra's algorithm for extraction of shortest paths in directed multigraphs. J Comput Sci, 9(3), pp.377-82.

Brecht, H., Dasgupta, S., Laplante, B., Murray, S. and Wheeler, D., 2012. Sea-level rise and storm surges: High stakes for a small number of developing countries. The Journal of Environment \& Development, 21(1), pp.120-138.

Brinkman, J.J. and Hartman, M., 2008. Jakarta flood hazard mapping framework. World Bank Report (unpublished). At

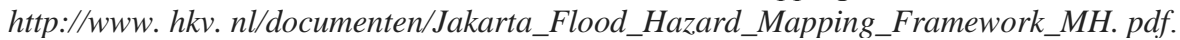

Caljouw, M., Nas, P.J. and Pratiwo, M.R., 2005. Flooding in Jakarta: Towards a blue city with improved water management. Bijdragen tot de taal-, land-en volkenkunde/Journal of the Humanities and Social Sciences of Southeast Asia, 161(4), pp.454-484.

Castillo-Effer, M., Quintela, D.H., Moreno, W., Jordan, R. and Westhoff, W., 2004, November. Wireless sensor networks for flash-flood alerting. InDevices, Circuits and Systems, 2004. Proceedings of the Fifth IEEE International Caracas Conference on (Vol. 1, pp. 142-146). IEEE.

Cembrano, G., Quevedo, J., Salamero, M., Puig, V., Figueras, J. and Mart1, J., 2004. Optimal control of urban drainage systems. A case study. Control Engineering Practice, 12(1), pp.1-9.

Chang, L.C. and Chang, F.J., 2009. Multi-objective evolutionary algorithm for operating parallel reservoir system. Journal of hydrology, 377(1), pp.12-20.

Chiu, P.L. and Lin, F.Y., 2004, May. A simulated annealing algorithm to support the sensor placement for target location. In Electrical and Computer Engineering, 2004. Canadian Conference on (Vol. 2, pp. 867-870). IEEE.

Comboul, M. and Ghanem, R., 2012. Value of information in the design of resilient water distribution sensor networks. Journal of Water Resources Planning and Management, 139(4), pp.449-455.

Costa, D., Burlando, P. and Priadi, C., 2016. The importance of integrated solutions to flooding and water quality problems in the tropical megacity of Jakarta. Sustainable Cities and Society, 20, pp.199-209.

Deb, K., Pratap, A., Agarwal, S. and Meyarivan, T.A.M.T., 2002. A fast and elitist multiobjective genetic algorithm: NSGA-II. IEEE transactions on evolutionary computation, 6(2), pp.182-197.

De Stefano, M., Gherlone, M., Mattone, M., Di Sciuva, M. and Worden, K., 2015. Optimum sensor placement for impact location using trilateration.Strain, 51(2), pp.89-100.

Eliades, D.G., Michaelides, M.P., Panayiotou, C.G. and Polycarpou, M.M., 2013. Security-oriented sensor placement in intelligent buildings. Building and environment, 63, pp.114-121.

Fang, H., Wang, Q., Tu, Y.C. and Horstemeyer, M.F., 2008. An efficient non-dominated sorting method for evolutionary algorithms. Evolutionary computation, 16(3), pp.355-384.

Few, R., 2003. Flooding, vulnerability and coping strategies: local responses to a global threat. Progress in Development Studies, 3(1), pp.43-58.

Georgakakos, K.P., 1986. On the design of national, real-time warning systems with capability for site-specific, flashflood forecasts. Bulletin of the American Meteorological Society, 67(10), pp.1233-1239.

Gonçalves, J., Martins, A. and Neves, L., 2016. Methodology for real impact assessment of the best location of distributed electric energy storage. Sustainable Cities and Society.

Guan, J., Aral, M.M., Maslia, M.L. and Grayman, W.M., 2006. Optimization model and algorithms for design of water sensor placement in water distribution systems. In 8th Annual Symp. on Water Distribution Systems Analysis (pp. 1-16). New York: Environmental and Water Resources Institute of ASCE (EWRI of ASCE).

Güney, E., Aras, N., Altınel, İ.K. and Ersoy, C., 2012. Efficient solution techniques for the integrated coverage, sink location and routing problem in wireless sensor networks. Computers \& Operations Research, 39(7), pp.15301539.

Hallegatte, S., Green, C., Nicholls, R.J. and Corfee-Morlot, J., 2013. Future flood losses in major coastal cities. Nature climate change, 3(9), pp.802-806.

Hart, W.E. and Murray, R., 2010. Review of sensor placement strategies for contamination warning systems in drinking water distribution systems. Journal of Water Resources Planning and Management, 136(6), pp.611-619.

Hartono, D.M., Novita, E., Gusniani, I. and Oriza, I.I.D., 2010. The role of water supply and sanitation during floods: Case study of flood disaster in five regions of jakarta. International Journal of Technology, 1(1), pp.29-37.

Holderness, T. and Turpin, E., 2015. White paper-PetaJakarta. org: Assessing the role of social media for civic comanagement during monsoon flooding in Jakarta, Indonesia. University of Wollongong, Wollongong.

Hughes, D., Greenwood, P., Blair, G., Coulson, G., Pappenberger, F., Smith, P. and Beven, K., 2006, September. An intelligent and adaptable grid-based flood monitoring and warning system. In Proceedings of the UK eScience All Hands Meeting (p. 10).

Hung, N.Q., Babel, M.S., Weesakul, S. and Tripathi, N.K., 2009. An artificial neural network model for rainfall forecasting in Bangkok, Thailand. Hydrology and Earth System Sciences, 13(8), pp.1413-1425.

Islam, M.S., Sadiq, R., Rodriguez, M.J., Francisque, A., Najjaran, H. and Hoorfar, M., 2011. Leakage detection and location in water distribution systems using a fuzzy-based methodology. Urban Water Journal, 8(6), pp.351-365. 
Kessler, A., Ostfeld, A. and Sinai, G., 1998. Detecting accidental contaminations in municipal water networks. Journal of Water Resources Planning and Management, 124(4), pp.192-198.

Krause, A., Guestrin, C., Gupta, A. and Kleinberg, J., 2006, April. Near-optimal sensor placements: Maximizing information while minimizing communication cost. In Proceedings of the 5th international conference on Information processing in sensor networks (pp. 2-10). ACM.

Krause, A., Leskovec, J., Guestrin, C., VanBriesen, J. and Faloutsos, C., 2008a. Efficient sensor placement optimization for securing large water distribution networks. Journal of Water Resources Planning and Management, 134(6), pp.516-526.

Krause, A., Singh, A. and Guestrin, C., 2008b. Near-optimal sensor placements in Gaussian processes: Theory, efficient algorithms and empirical studies. Journal of Machine Learning Research, 9(Feb), pp.235-284.

Lau, C.L., Smythe, L.D., Craig, S.B. and Weinstein, P., 2010. Climate change, flooding, urbanisation and leptospirosis: fuelling the fire?. Transactions of the Royal Society of Tropical Medicine and Hygiene,104(10), pp.631-638.

Lee, B.H., Deininger, R.A. and Clark, R.M., 1991. Locating monitoring stations in water distribution systems. Journal (American Water Works Association), pp.60-66.

Li, H., 2003. Management of coastal mega-cities - a new challenge in the 21st century. Marine Policy, 27(4), pp.333337.

Malano, H.M., Chien, N.V. and Turral, H.N., 1999. Asset management for irrigation and drainage infrastructureprinciples and case study. Irrigation and Drainage systems, 13(2), pp.109-129.

Nasir, H.A. and Muhammad, A., 2011. Control of Very-Large Scale Irrigation Networks: A CPS Approach in a Developing-World Setting. IFAC Proceedings Volumes, 44(1), pp.10739-10745.

Neteler, M., Bowman, M.H., Landa, M. and Metz, M., 2012. GRASS GIS: A multi-purpose open source GIS. Environmental Modelling \& Software, 31, pp.124-130.

Ni, J., Sun, L., Li, T., Huang, Z. and Borthwick, A.G., 2010. Assessment of flooding impacts in terms of sustainability in mainland China. Journal of environmental management, 91(10), pp.1930-1942.

Obe, R.O. and Hsu, L.S., 2015. PostGIS in action. Manning Publications Co..

Ogie, R., Holderness, T., Dunbar, M. and Turpin, E., 2016. Spatio-topological network analysis of hydrological infrastructure as a decision support tool for flood mitigation in coastal mega-cities. Environment and Planning B: Planning and Design, p.0265813516637608.

Ogie, R.I., Dunn, S., Holderness, T. and Turpin, E., 2017. Assessing the vulnerability of pumping stations to trash blockage in coastal mega-cities of developing nations. Sustainable Cities and Society, 28, pp.53-66.

Ostfeld, A., Uber, J.G., Salomons, E., Berry, J.W., Hart, W.E., Phillips, C.A., Watson, J.P., Dorini, G., Jonkergouw, P., Kapelan, Z. and di Pierro, F., 2008. The battle of the water sensor networks (BWSN): A design challenge for engineers and algorithms. Journal of Water Resources Planning and Management, 134(6), pp.556-568.

Parrott, D., Li, X. and Ciesielski, V., 2005, September. Multi-objective techniques in genetic programming for evolving classifiers. In 2005 IEEE Congress on Evolutionary Computation (Vol. 2, pp. 1141-1148). IEEE.

Perelman, L. and Ostfeld, A., 2011. Topological clustering for water distribution systems analysis. Environmental Modelling \& Software, 26(7), pp.969-972.

Pleau, M., Colas, H., Lavallée, P., Pelletier, G. and Bonin, R., 2005. Global optimal real-time control of the Quebec urban drainage system. Environmental Modelling \& Software, 20(4), pp.401-413.

Preis, A. and Ostfeld, A., 2006. Multiobjective sensor design for water distribution systems security. In 8th Annual Symp. on Water Distribution Systems Analysis (pp. 1-17). New York: Environmental and Water Resources Institute of ASCE (EWRI of ASCE).

Preis, A. and Ostfeld, A., 2008. Multiobjective contaminant sensor network design for water distribution systems. Journal of Water Resources Planning and Management, 134(4), pp.366-377.

Preis, A., Whittle, A. and Ostfeld, A., 2011. Multi-objective optimization for conjunctive placement of hydraulic and water quality sensors in water distribution systems. Water Science and Technology: Water Supply, 11(2), pp.166171.

Saputelli, L., Nikolaou, M. and Economides, M.J., 2006. Real-time reservoir management: A multiscale adaptive optimization and control approach. Computational Geosciences, 10(1), pp.61-96.

Sedlar, F., 2016. Inundated Infrastructure: Jakarta's Failing Hydraulic Infrastructure. Michigan Journal of Sustainability, 4; doi: http://dx.doi.org/10.3998/mjs.12333712.0004.004

Shastri, Y. and Diwekar, U., 2006. Sensor placement in water networks: A stochastic programming approach. Journal of water resources planning and management, 132(3), pp.192-203.

Shukla, N., Ceglarek, D. and Tiwari, M.K., 2015. Key characteristics-based sensor distribution in multi-station assembly processes. Journal of intelligent manufacturing, 26(1), pp.43-58.

Shukla, N., Tiwari, M.K. and Shankar, R., 2009. Optimal sensor distribution for multi-station assembly process using chaos-embedded fast-simulated annealing. International Journal of Production Research, 47(1), pp.187-211.

Sims, J., 2013. The No-Nonsense Guide to Flood Safety. Lulu Books \& Beyond the Spectrum Books

Smith, P.J., Hughes, D., Beven, K.J., Cross, P., Tych, W., Coulson, G. and Blair, G., 2009. Towards the provision of site specific flood warnings using wireless sensor networks. Meteorological Applications, 16(1), pp.57-64.

Southworth, F., 2008. Multi-criteria sensor placement for emergency response. Applied Spatial Analysis and Policy, 1(1), pp.37-58.

Tadeu, S.F., Alexandre, R.F., Tadeu, A.J., Antunes, C.H., Simões, N.A. and da Silva, P.P., 2016. A comparison between cost optimality and return on investment for energy retrofit in buildings-A real options perspective. Sustainable Cities and Society, 21, pp.12-25. 
Takagi, H., Esteban, M., Mikami, T. and Fujii, D., 2016. Projection of coastal floods in 2050 Jakarta. Urban Climate, 17, pp.135-145.

Tingsanchali, T., 2012. Urban flood disaster management. Procedia engineering, 32, pp.25-37.

Tran, K.D., 2009. An improved Non-dominated Sorting Genetic Algorithm-II (ANSGA-II) with adaptable parameters. International Journal of Intelligent Systems Technologies and Applications, 7(4), pp.347-369.

Treml, E.A., Halpin, P.N., Urban, D.L. and Pratson, L.F., 2008. Modeling population connectivity by ocean currents, a graph-theoretic approach for marine conservation. Landscape Ecology, 23(1), pp.19-36.

Turpin, E. and Holderness, T., 2015a. PetaJakarta.org Major Open Data Collection-Pumps and Floodgates in Jakarta, Indonesia. SMART Infrastructure Facility, University of Wollongong

Turpin, E. and Holderness, T., 2015b. PetaJakarta.org Major Open Data Collection-Waterways in Jakarta, Indonesia. SMART Infrastructure Facility, University of Wollongong

USGS, 2015. Shuttle Radar Topography Mission (SRTM) 1 Arc-Second SRTM data set, Available online https://lta.cr.usgs.gov/SRTM1Arc (accessed 15/08/2016)

Valdes, J.B. and Marco, J.B., 1995. Managing reservoirs for flood control. In Proceedings of the US-Italy Research Workshop on the Hydrometeorology, Impacts, and Management of Extreme Floods, Perugia, Italy (pp. 1-13).

Vamvakeridou-Lyroudia, L.S., Walters, G.A. and Savic, D.A., 2005. Fuzzy multiobjective optimization of water distribution networks. Journal of water resources planning and management, 131(6), pp.467-476.

Ward, P.J., Marfai, M.A., Yulianto, F., Hizbaron, D.R. and Aerts, J.C.J.H., 2011. Coastal inundation and damage exposure estimation: a case study for Jakarta. Natural Hazards, 56(3), pp.899-916.

Weickgenannt, M., Kapelan, Z., Blokker, M. and Savic, D.A., 2010. Risk-based sensor placement for contaminant detection in water distribution systems. Journal of Water Resources Planning and Management, 136(6), pp.629636.

Wenzel, F., Bendimerad, F. and Sinha, R., 2007. Megacities-megarisks.Natural Hazards, 42(3), pp.481-491.

World Bank, 2010. JAKARTA | Urban Challenges in a Changing Climate Mayors' Task Force On Climate Change, Disaster Risk \& The Urban Poor, Available http://documents.worldbank.org/curated/en/132781468039870805/pdf/650180WP0Box360ange0Jakarta0English. pdf (accessed 27/09/2016).

Wu, Z.Y. and Walski, T., 2006, August. Multi objective optimization of sensor placement in water distribution systems. In 8th Annual Symp. on Water Distribution Systems Analysis. New York: Environmental and Water Resources Institute of ASCE (EWRI of ASCE).

Xu, J., Fischbeck, P.S., Small, M.J., VanBriesen, J.M. and Casman, E., 2008. Identifying sets of key nodes for placing sensors in dynamic water distribution networks. Journal of Water Resources Planning and Management, 134(4), pp.378-385.

Yamashita, S., Watanabe, R. and Shimatani, Y., 2016. Smart adaptation activities and measures against urban flood disasters. Sustainable Cities and Society, 27, pp.175-184.

Younis, M. and Akkaya, K., 2008. Strategies and techniques for node placement in wireless sensor networks: A survey. Ad Hoc Networks, 6(4), pp.621-655.

Zhou, A., Qu, B.Y., Li, H., Zhao, S.Z., Suganthan, P.N. and Zhang, Q., 2011. Multiobjective evolutionary algorithms: A survey of the state of the art. Swarm and Evolutionary Computation, 1(1), pp.32-49. 